\title{
Phobic COVID-19 Disorder Scale: Development, Dimensionality, and Item-Structure Test
}

\author{
Mohd Nasir ${ }^{1} \cdot$ Mohd Adil $^{2} \cdot$ Mukesh Kumar $^{3}$ \\ Accepted: 17 May 2021 / Published online: 7 July 2021 \\ (C) Springer Science+Business Media, LLC, part of Springer Nature 2021
}

\begin{abstract}
Over the century, the world has witnessed a number of pandemics - such as plague, Spanish flu, smallpox, and tuberculosis. Such pandemics have not only resulted in a great loss to human lives but have also affected the economy of many countries. COVID-19, declared as global pandemic by the World Health Organization (WHO), is the latest in this series which has hit the world since the last quarter of 2019. Although a number of scales exist to assess fear and distress of individuals related to COVID-19, it is well articulated in the extant literature that sometimes the proposed scales are context specific and lack applicability in multi-cultural environment as also the factors' structure of the scale are fit from the context of audience from certain geographical regions. Thus, a need was felt to evaluate the FCV-19S and propose and statistically validate a new COVID-19-based scale called Phobic COVID19 Disorder scale (Phobic-19 scale). A structured e-questionnaire in English was used to collect the data from the respondents. A 12-item, three-dimensional (fear, anxiety, and distress) scale was developed to capture the emotions of general populations towards COVID-19. The study analyzes the dimensionality and item structure of the scale through exploratory factor analysis and further validated with the help of confirmatory factor analysis. The results show that the Phobic-19 scale has a strong internal consistency along with better psychometric characteristics. Mass replication and a large number of empirical research using the Phobic-19 scale would instill confidence amongst scholars and practitioners in the results. The findings also highlight that the results would help to advance our understanding by providing critical information related to COVID-19 and ensure that the scale provides accurate and usable data.
\end{abstract}

Keywords Item structure - Dimensionality Scale development $\cdot$ Scale validation $\cdot$ CFA $\cdot$ COVID19. Phobic-19

Over the century, the world has witnessed a number of pandemics - such as plague, Spanish flu, smallpox, and tuberculosis. Such pandemics have not only resulted in a great loss to

Mohd Nasir

mohdnasir22@gmail.com

Extended author information available on the last page of the article 
human lives but have also affected the economy of many countries. COVID-19, a global pandemic, is the latest in this series, which has hit the world since the last quarter of 2019 (Soraci et al., 2020). According to WHO (2020), about 200 countries have reportedly been affected by the COVID-19 pandemic until May 2020. The threat of COVID-19 is quite eminent as it carries a very high infection rate (Baud et al., 2020; Sakib et al., 2020), and to check its wide spread, countries have resorted to lockdown at national level suspending all academic and unnecessary non-essential commercial activities.

Unpleasant news can easily make an individual anxious. Similarly, a news related to a pandemic can certainly fill individuals with "anxiety," "depression," and "stress" (Noronha, 2020). With several rounds of nationwide lockdown in India, individuals' routine life came to a standstill. Further, confinement within the four walls of a room during lockdown, coupled with gloomy state of affairs of business and layoffs, people find themselves amidst a state of nervousness and mental stress (Noronha, 2020; Satici et al., 2020; Xiang, 2020). Excessive fear in terms of both social and economic magnitudes impacted individuals' rational thinking behavior which may have a bearing upon the mental health condition and psycho-socio challenges (Sakib et al., 2020). Moreover, uncertainty related to the outcomes of the infected individuals, familiarity with patients, and restrictions imposed by the government for public safety has caused a feeling of fear amongst individuals across the world (Soraci et al., 2020). Additionally, the extant literature related to the past outbreak has already highlighted the influence of fear and its undesirable psychological outcomes in worsening the harmful effect of an infectious disease (Soraci et al., 2020).

Moreover, driven by the sensational headlines in the electronic and print media, fear can cause an individual to oscillate between phobia and denial, on one hand, while on the other, stigmatizes infected people racially for being the cause of such infectious disease (Noronha, 2020; Soraci et al., 2020). Eventually, a number of psychological disorders, such as depression and anxiety, have also been reported to be linked with fear in earlier epidemics, vastly influencing individuals' quality of life (Ford et al., 2019; Huang et al., 2020). In addition, people may experience stigmatization caused by fear and panic about COVID-19 (Zhang et al., 2020) and pointed out that they are scared of getting contacted with infected individuals (Lin, 2020). Similarly, such outcomes appear to be particularly relevant with the current pandemic situation, as social distancing has been previously found to be strongly intertwined with psychological outcome like anxiety and depression in both young and older individuals (Matthews et al., 2019; Santini et al., 2020).

Although it appears pertinent and an interesting topic amongst the researchers worldwide in the area of medical sciences, it has been well acknowledged in the field of social sciences too. Consequently, several researchers (e.g., Bhuiyan et al., 2020; Pakpour et al., 2020; Qiu et al., 2020; Wang et al., 2020) have attempted to observe its impact on individual's psyche and on mental health (Mamun \& Griffiths, 2020). However, studies primarily considering the psychological impact of COVID-19 on mental health is scarce (Mamun \& Griffiths, 2020; Satici et al., 2020; Schimmenti et al., 2020) particularly in Indian context.

This may eventually result in a change in an individual's buying habit and consumption pattern. Thus, it is of great concern to develop and test a comprehensive instrument to measure the phobic disorder caused by COVID-19. Previous researchers have attempted to develop and validate varied scales measuring fear of COVID-19 scale (Ahorsu et al., 2020); COVID stress scale, CSS (Taylor et al., 2020); and hospital anxiety and depression scale, HADS (Zigmond $\&$ Snaith, 1983). However, most of these scales were developed and validated in different settings unlike India. Similarly, threat caused by COVID-19 and its effects on individual's 
psychological responses have also been acknowledged (Bhuiyan et al., 2020; Qiu et al., 2020; Wang et al., 2020). Moreover, psychological responses particularly anxiety and fear are significant factors playing key role in determining individual's behavior (Pakpour et al., 2020) and social disruptive behavior due to high level of anxiety (Lin, 2020; Taylor et al., 2020). Additionally, the fear of COVID-19 is also found to be linked with individuals' psychological distress and life satisfaction (Satici et al., 2020). Moreover, India has ranked 4th amongst the world's worst affected countries by COVID-19 and the first amongst the developing countries during the month of June 2020 (The Times of India, 2020).

Therefore, considering the importance of COVID-19 in the present scenario and dearth of empirical studies in Indian context, the prime objective of the current research is multifold(a) to design and develop a comprehensive instrument which captures "the fear" together with "the anxiety" and "the depression." This will offer a deeper insight to researchers, marketers, policy makers, and other stakeholders in assessing individual's psychological responses especially with reference to phobic disorder and social disruptive behavior; (b) to test the item structure, dimensionality, and psychometric properties of the proposed scale; and (c) to compare statistically the existing scales vis-a-vis the proposed Phobic-19 scale in Indian context.

\section{Research Methodology}

\section{Study Sample}

The target audience considered under this study consists of the general population from India above 18 years in age. The data was collected from the top four states of India highly affected by COVID-19 pandemic. For which Maharashtra, Delhi, Karnataka, and Gujarat were selected based on the data available up to April 2020 (Financial Express, 2020). Thus, it is presumed to be a suitable representative of the population for the purpose of the present study.

\section{Questionnaire Development and Pilot Study}

Based on the suggestions of Adil et al. (2013a, b), Slavec and Drnovšek (2012), and Salhieh et al. (2011), we designed an e-survey to test the psychometric properties of the Phobic-19 scale in Indian setting. Analysis of the existing literature on fear, depression, and anxiety (Ahorsu et al., 2020; Soraci et al., 2020) led the researchers to draw the items for the present scale and adapt it according to the study context. For this purpose, we adopted four items from fear of COVID-19 scale, six and five items from scale measuring depression and anxiety, respectively. Consequently, 15-item Phobic-19 was initially designed and tested under this study. To ensure the adequate validity of the questionnaire in terms of its structures, contents, layout, etc., a pre-test was conducted on 2 faculty members and 3 research scholars of the department of psychology belonging to a centrally funded university.

A pilot study was also conducted on the general population. Respondents above the age of 18 years were invited to be a part of the e-survey. A total of 35 responses were generated and found suitable for further process. The respondents were approached through an e-questionnaire and were requested to rate their opinion on a 5-point Likert scale ranging from 5 (strongly agree) to 1 (strongly disagree). Based on the inputs received during the pre-test and the pilot survey, items were appropriately re-phrased 
keeping in mind the social and economic background of Indian respondents. The results of the pilot survey exhibit that the value of McDonald's Omega $(\omega)$ for each construct met the threshold level of 0.7 (Hayes \& Coutts, 2020).

\section{Data Collection}

To make sure that the e-questionnaire was administered on the target sample, a crosscheck question was used to check out whether the participants were aware of COVID-19. Only those who responded "yes" were considered eligible for the e-survey. Five-point Likert scale ranging from 5 (strongly agree) to 1 (strongly disagree). To collect the data under the current study, researchers have adopted the snowball sampling method. By following "Ten (10) times rule i.e. 10 times the number of the independent variables of the most complex in the structural or formative measurement model" (Hair et al., 2019), 600 emails were sent under stage I, of which 262 were returned, with only 237 were found complete and considered for further analysis. While under stage II, a total of 1000 emails were sent, of which 532 emails were responded and 487 responses were found complete in all respect.

The e-survey resulted in 237 responses under stage I and 487 responses under stage II. Table 1 presents the demographic profile of the targeted samples. Under stage I, almost $77 \%$ of the respondents were reported to be male; relatively younger in age with around $54.43 \%$ up to the age of 30 years. While considering respondents' educational status, about $30.80 \%$ of them were graduates. While under stage II, almost $80.90 \%$ of the respondents were male; more than half of the respondents are relatively in the younger age group (18-30). A majority of the respondents were graduates. More than $30 \%$ of the respondents were student under both the stages.

Table 1 Demographic profile of the respondents

\begin{tabular}{|c|c|c|c|c|c|}
\hline \multirow[t]{2}{*}{ Variable } & & \multicolumn{2}{|l|}{ Stage I } & \multicolumn{2}{|l|}{ Stage II } \\
\hline & & $n=237$ & Percent & $n=487$ & Percent \\
\hline \multirow[t]{2}{*}{ Gender } & Male & 183 & 77.21 & 394 & 80.90 \\
\hline & Female & 54 & 22.79 & 93 & 19.10 \\
\hline \multirow[t]{6}{*}{ Age } & $18-25$ & 62 & 26.16 & 136 & 27.93 \\
\hline & $26-30$ & 67 & 28.27 & 142 & 29.09 \\
\hline & $31-35$ & 36 & 15.19 & 79 & 16.22 \\
\hline & $36-40$ & 32 & 13.50 & 69 & 14.17 \\
\hline & $41-45$ & 22 & 09.28 & 36 & 7.39 \\
\hline & 45 and above & 18 & 07.60 & 25 & 5.13 \\
\hline \multirow[t]{4}{*}{ Occupation } & Student & 72 & 30.38 & 151 & 31.01 \\
\hline & Business & 48 & 20.25 & 93 & 19.10 \\
\hline & Service & 68 & 28.70 & 147 & 30.18 \\
\hline & Self-employed & 49 & 20.67 & 96 & 19.72 \\
\hline \multirow[t]{4}{*}{ Education } & High school & 58 & 24.47 & 107 & 21.97 \\
\hline & Intermediate & 68 & 28.69 & 143 & 29.36 \\
\hline & Graduate & 73 & 30.80 & 154 & 31.62 \\
\hline & Post-graduate & 38 & 16.04 & 83 & 17.04 \\
\hline
\end{tabular}

Source: primary data 


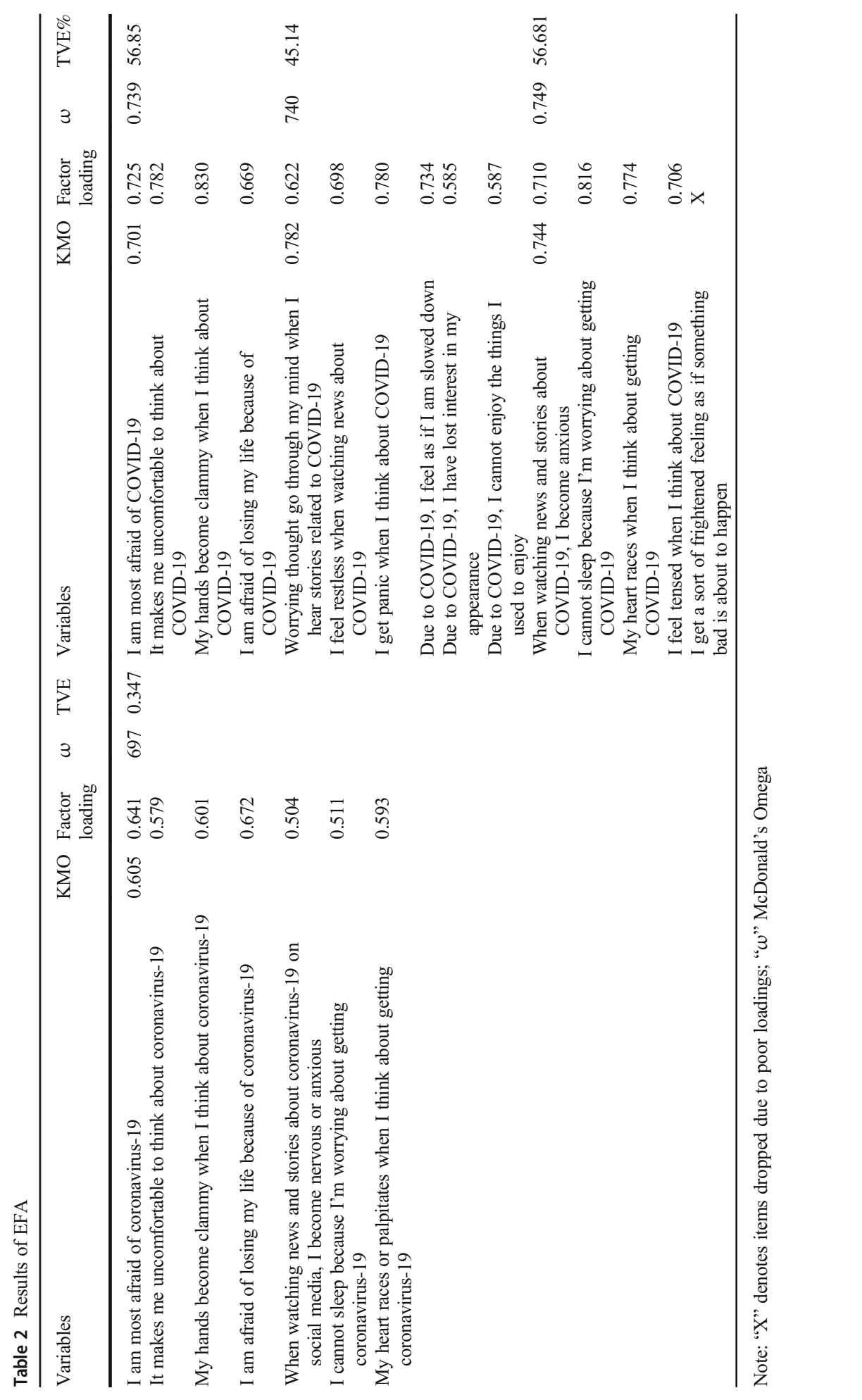

\section{包 Springer}




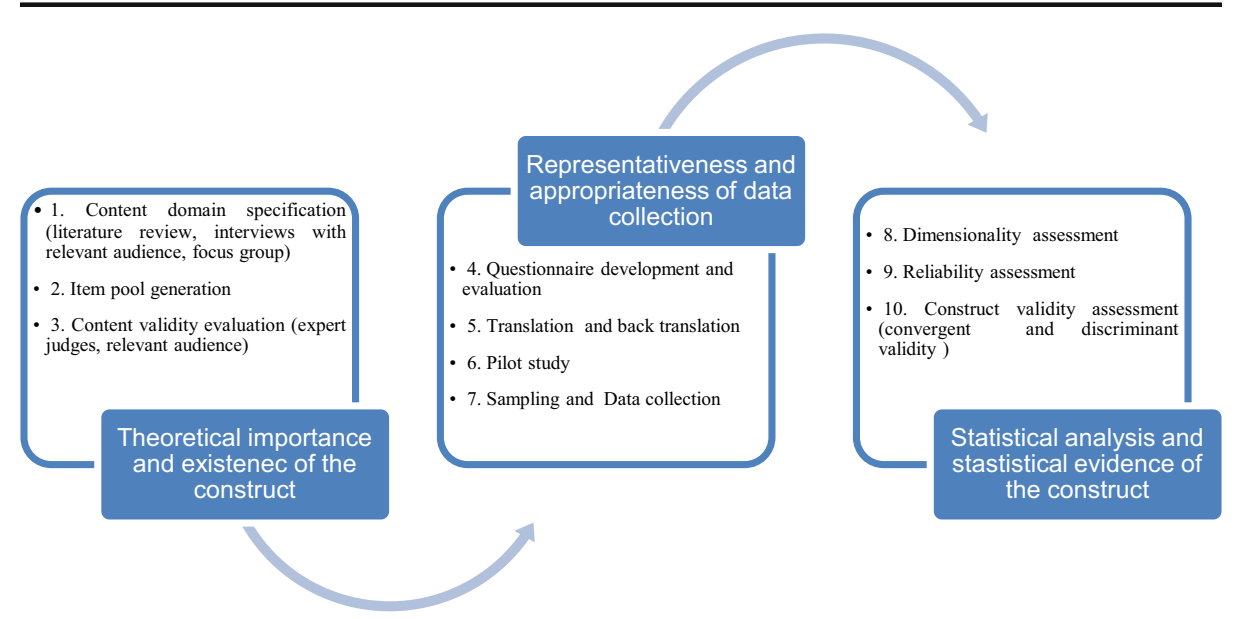

Fig. 1 Steps in questionnaire development. Source: Slavec and Drnovšek (2012), Nasir and Adil (2020)

\section{Analysis}

\section{Reliability and Validity}

In line with the suggestions of Hayes and Coutts (2020), McDonald's Omega ( $\omega)$ was used to test the internal consistency of the scale which helps in assessing the capability of the scale items to measure the same factor. Scale items that loaded on to the same construct are supposed to have a positive correlation amongst them and show adequate internal consistency of a scale measuring the same construct. Each construct met the standard cut-off value of 0.7 (Hair et al., 2019).

The degree to which scale measures what it is intended to measure is termed as validity of scale. To ensure the adequate validity of the scale, convergent and discriminant validity should be checked. The most important empirical support for the current scale comes from the original studies. It forms a primary basis, for developing COVID-19 Disorder measurement system. Even though the original scales were a standard measure, however, it might not show the same results in different settings. It is possible that the number dimensions that might emerge may not be the same as they were in the original study. Hence, dimensionality and item structure of a scale is often bound by sample size and contexts (Dunlap et al., 2000). Therefore, there is an urgent need to test the psychometric properties, dimensionality, and item structure of the Phobic-19 scale in Indian context.

\section{Item Reduction and Factor Analysis}

Factor analysis is a statistical method that explains the variation in observed variables and correlate variables in terms of a potentially lower number of unobserved variables called factors. Exploratory factor analysis was conducted using principal component analysis with varimax rotation (Ali \& Adil, 2014). The emerged three dimensions were selected in terms of Bartlett's test of sphericity and Kaiser- Meyer-Olkin (KMO) measure of sampling adequacy (see Table 2).

The identified 3 factors explained $63.104 \%$ of the total variances of the variables. The dimension "Fear" includes four items $(\omega=0.739)$. The remaining two factors, i.e., 
Table 3 Measurement model I

\begin{tabular}{llllll}
\hline & No of Items & Composite reliability & AVE & Omega & Factor loading \\
\hline Fear & 04 & 0.790 & 0.490 & 0.774 & $0.60-0.75$ \\
Depression & 04 & 0.799 & 0.501 & 0.785 & $0.61-0.78$ \\
Anxiety & 04 & 0.805 & 0.509 & 0.801 & $0.66-0.77$ \\
\hline
\end{tabular}

Note: $\mathrm{AVE}=$ average variance extracted $;$ Omega $=$ McDonald's Omega

"depression" and "anxiety," were measured with 6 (D1-D6) and 4 (A1-A4) items, respectively, and both reported the McDonald's Omega value of 0.7 and above (i.e., $\omega=0.740$ and $\omega=$ 0.749 , respectively).

\section{Measurement Model}

Sadiq et al. (2019) and Gupta and Adil (2014) reported that EFA suffers from a number of limitations, such as cross loadings, oversimplicity, difficulty to draw reliable inferences, "the confirmatory factor analysis" (CFA) is recommended. The current research has adopted the methodology suggested by Gerbing and Anderson (1988) to evaluate the measurement model. Thus, CFA was conducted on the following factors - fear, depression, and anxiety. The standardized item loading for each dimension was stated, followed by model fit test. (Fig. 1)

Table 3 and Table 4 summarize the overall key fit statistics obtained for the 12-item Phobic19 model (model I and model II). The reported indices for Phobic-19 model were proved to be good fit and robust. The obtained values for model I was GFI (0.919), AGFI (0.875), CFI (0.908), CMIN/df (1.783), and RMSEA (0.065) (Sadiq \& Adil, 2021). The AGFI value was found to be considerable and close to the recommended value of 0.9. Therefore, the final model fit indices indicate that all the goodness-of-fit measures met the acceptable levels (Fig. 2). Moreover, for further model validation and comparison with the obtained findings of model I, 12-item Phobic-19 scale was re-tested under stage II (Fig. 3). Another set of data was generated from 487 respondents and results show a better standard fit and values, when compared with the model I. The values for GFI, AGFI, and CFI were obtained as 0.952, 0.901, and 0.915 , respectively. The value for CMIN/df was 1.413. Lastly, RMSEA was 0.049 . Thus, model II confirms both the dimensionality and item structure of model I. Hence, 3-dimensional model with 12-item Phobic-19 scale was found to be robust and psychometrically sound. Table 5

The convergent validity was also ascertained. To assess convergent validity, standardized factor loadings, composite reliability, and AVE were computed (Hair et al., 2019; Sadiq et al., 2021a, 2021b). The suggested threshold level for loading values are considered at above 0.05 ; the AVE and CR value should be above 0.5 and 0.7, respectively (Hair et al., 2019; Nasir \& Adil, 2020; Sadiq et al., 2021b). Table 3 shows the results of model I. Except for one of the

Table 4 Measurement model II (re-test model)

\begin{tabular}{llllll}
\hline & No of Items & Composite reliability & AVE & Omega & Factor loading \\
\hline Fear & 04 & 0.820 & 0.534 & 0.787 & $0.69-0.77$ \\
Depression & 04 & 0.834 & 0.557 & 0.797 & $0.69-0.81$ \\
Anxiety & 04 & 0.861 & 0.608 & 0.813 & $0.69-0.86$ \\
\hline
\end{tabular}

Note: $\mathrm{AVE}=$ average variance extracted; Omega $=$ McDonald's Omega 


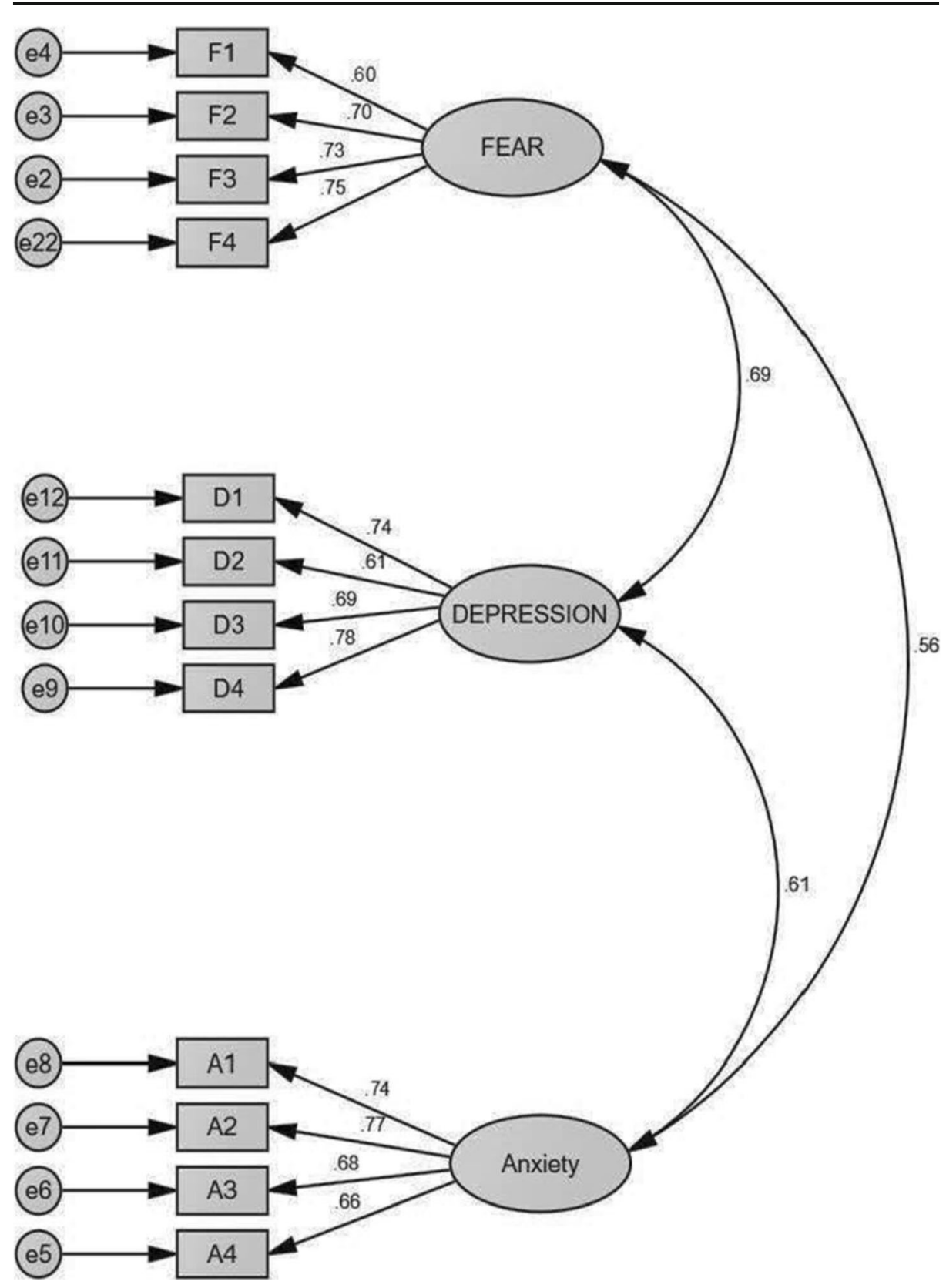

Fig. 2 Model I Phobic-19

construct, i.e., fear (0.490), the values for the remaining two constructs met the suggested standard level. Table 4 highlighted the results of model II, whereby the obtained indices surpassed the recommended values, confirming sufficient convergent validity. Further, to assess the discriminant validity, AVE for each construct was checked (Adil et al., 2015; Ullah \& Adil, 2016), and the obtained values oscillated from 0.534 to 0.608 . 


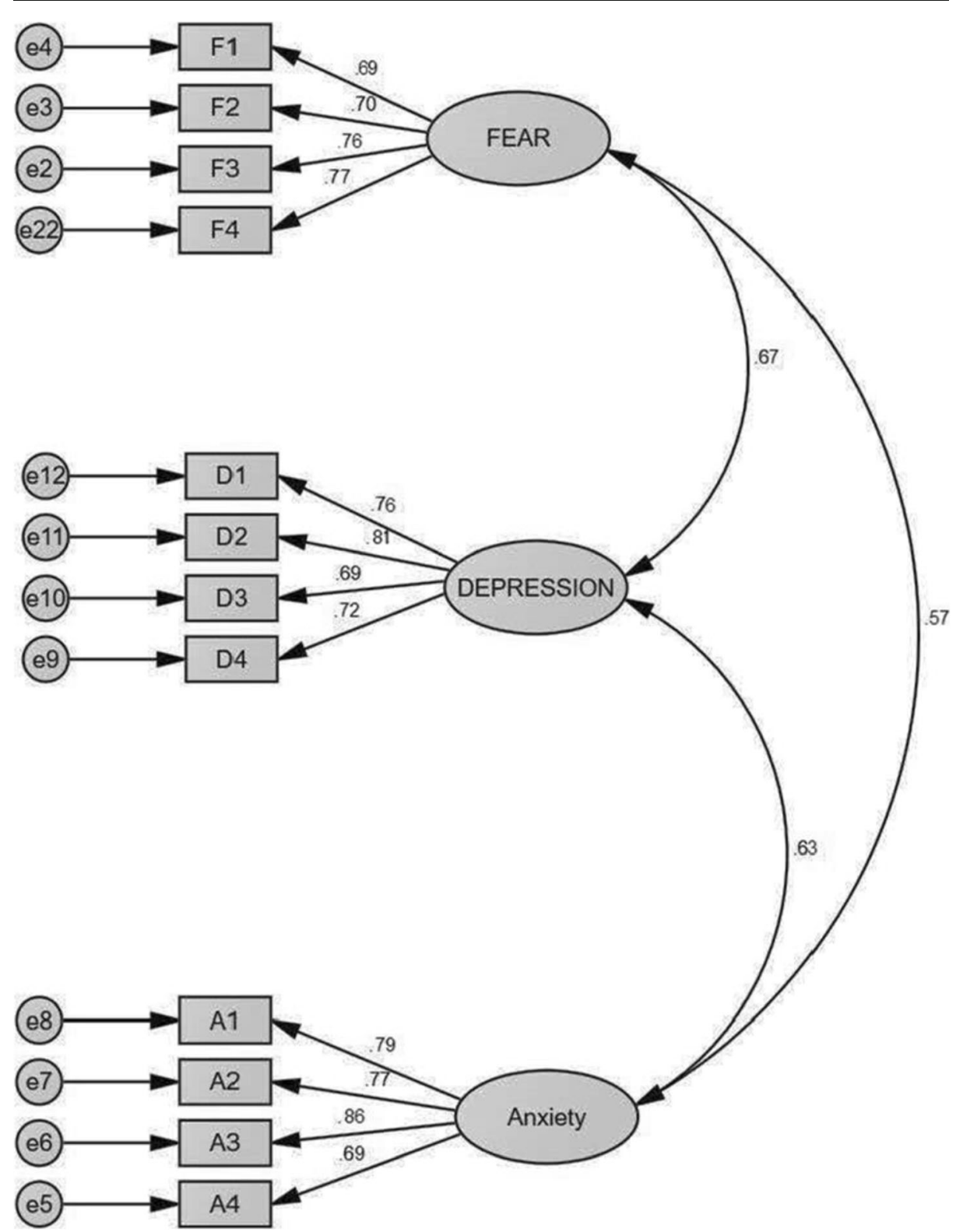

Fig. 3 Model II (re-test model)

\section{Discussion and Conclusion}

The prime objective of the current research was to evaluate the psychometric properties of Ahorsu et al.'s (2020) FCV-19S and compared it with the newly developed and validated Phobic-19 scale by employing rigorous statistical analyses. By following the suggested systematic approach for item creation and development of a new scale, the Phobic-19 scale was developed. Twelve-item, 3-dimensional Phobic-19 scale serves as a guide to assess the 
Table 5 Goodness of fit indices for the model

\begin{tabular}{|c|c|c|c|c|c|}
\hline $\begin{array}{l}\text { Fit } \\
\text { indicators }\end{array}$ & $\mathrm{CMIN} / \mathrm{df}$ & GFI & AGFI & CFI & RMSEA \\
\hline Threshold & $\begin{array}{c}<3 \text { good } ;<5 \\
\text { sometimes } \\
\text { permissible }\end{array}$ & $>0.95$ & $>0.80$ & $\begin{array}{l}>0.95 \text { great }>0.90 \text { traditional } \\
\quad>0.80 \text { sometimes permissible }\end{array}$ & $\begin{array}{r}<0.05 \text { good; } 0.05-0.10 \\
\quad \text { moderate } ;>0.10 \text { bad }\end{array}$ \\
\hline Model I & 1.783 & 0.919 & 0.875 & 0.908 & 0.065 \\
\hline $\begin{array}{l}\text { Model II } \\
\text { (re-test) }\end{array}$ & 1.413 & 0.952 & 0.901 & 0.915 & 0.049 \\
\hline
\end{tabular}

level of fear, anxiousness, and distress amongst individuals during this COVID-19 pandemic. The findings reveal that the Phobic-19 scale had (i) better standardized factor loadings and internal consistency, (ii) acceptable convergent and discriminant validity, (iii) confirmed dimensionality and item-structure of the scale, and (iv) significant explanation of the total variance as compared to FCV-19S.

Generally, researchers had elicited concerns related to scales' applicability in a diversecultural environmental setting. Scholars (such as, Nasir \& Adil, 2020; Nasir \& Adil, 2017; Khan, Khan and Adil, 2012) had argued that under certain conditions, the dimensionality and item structure of the scale are found to be context and sample specific (e.g., SERVQUAL and SERVPERF). Thus, there is always a need to test the psychometric properties of the FCV-19S. Given this, first, we developed a scale and tested it on the basis of sample I, while validated the results on a much larger sample II. The overall findings of the scale suggest that the 3 dimensional Phobic-19 scale is the best fit to capture individuals' emotions, such as fear, anxiety, and distress, amongst the general populations in a more holistic way as compared to other existing scales.

Mass replication in a large number of empirical studies using the Phobic-19 scale would instill confidence amongst scholars and practitioners in the results. The findings would help to advance our understanding by providing critical behavioral changes related to COVID-19 and ensure that the scale provides accurate and usable data. By using the 12-item scale, a researcher is expected to enhance the future of management and allied research areas.

\section{Limitation and Future Scope}

- Although researchers have attempted their best to undertake measures to make the sample as best representatives as possible, it may lack real representation of the population. As India is a land with rich and distinct cultures with vast geographic boundaries, the results might lack uniqueness in different settings. Therefore, future researchers should be motivated to consider sampling procedure which led to a wide generalizability of its results

- This research work also suffers from an urban biasness as participants were residing in urban areas and have overlooked the rural viewpoint. Since a major part of the Indian population resides in rural areas, it is essential to capture their opinion too. Therefore, future researchers need to focus on rural areas and should generate responses from rural audience as well, to map their view in the context of COVID-19.

- Response bias in the data cannot be ignored. Data might include the responses that were desirables from respondents' point of view. Some of the individuals might have also 
answered the survey misleadingly. Hence, steps need to be taken by the future researchers to control such bias.

- Further, the fact that the Indian people may have an unidentified differentiating characteristics and psyche from people of other countries generates concern. Thus, researchers from other nations must guard against generalizations of the research findings.

- Besides the above limitations, more number of replicative studies should be conducted in order to offer more definite evidences of reliability and validity of Phobic-19 scale.

\section{Declarations}

Conflict of Interest Authors do not have any conflict of interest with respect to this publication.

Ethical Approval Researchers have carried out the study in accordance to the standard ethical norms. Respondents, who volunteered themselves, were allowed to participate in the survey. All respondents were informed that their responses would remain anonymous and used for academic purpose only. Respondents were also allowed to withdraw their participation at any time.

\section{References}

Adil, M., Khan, M.N., \& Khan, K.M. (2013a). Exploring the relationships among service quality, customer satisfaction, complaint behaviour and loyalty in Indian urban retail banks: a confirmatory factor analytic approach. In Proceedings of the 5th IIMA Conference on Marketing in Emerging Economies, IIMAhmedabad, India (pp. 166-172)

Adil, M., Akhtar, A., \& Khan, M. N. (2013b). Refinement of internet banking service quality scale: a confirmatory factor analysis approach. International Journal of Services and Operations Management, 14(3), 336-354.

Adil, M., Khan, M. N., \& Ansari, S. A. (2015). 'Customers' perception towards bank service quality: a comparative study of Indian and Turkish customers'. In Proceedings of 6th IIMA Conference on Marketing in Emerging Economies (pp. 266-275). Indian Institute of Management Ahmedabad.

Ahorsu, D. K., Lin, C. Y., Imani, V., Saffari, M., Griffiths, M. D., \& Pakpour, A. H. (2020). The fear of COVID19 scale: development and initial validation. International journal of mental health and addiction. https:// doi.org/10.1007/s11469-020-00270-8.

Ali, A., \& Adil, M. (2014). Environmentalism and green consumer behavior: an empirical study on Indian students. IILM Management \& Change, 18(2), 107-125.

Baud, D., Qi, X., Nielsen-Saines, K., Musso, D., Pomar, L., \& Favre, G. (2020). Real estimates of mortality following COVID-19 infection. The Lancet Infectious Diseases, 20(7), 773.

Bhuiyan, A. I., Sakib, N., Pakpour, A. H., Griffiths, M. D., \& Mamun, M. A. (2020). COVID-19-related suicides in Bangladesh due to lockdown and economic factors: case study evidence from media reports. International Journal of Mental Health and Addiction. https://doi.org/10.1007/s11469-020-00307-y.

Dunlap, R. E., Van Liere, K. D., Mertig, A. G., \& Jones, R. E. (2000). New trends in measuring environmental attitudes: measuring endorsement of the new ecological paradigm: a revised NEP scale. Journal of Social Issues, 56(3), 425-442.

Ford, B. N., Yolken, R. H., Dickerson, F. B., Teague, T. K., Irwin, M. R., Paulus, M. P., \& Savitz, J. (2019). Reduced immunity to measles in adults with major depressive disorder. Psychological Medicine, 49(2), 243-249.

Gerbing, D. W., \& Anderson, J. C. (1988). An updated paradigm for scale development incorporating unidimensionality and its assessment. Journal of Marketing Research, 25(2), 186-192.

Gupta, N., \& Adil, M. (2014). Ascertaining the item structure of consumer based brand equity: a factor specific approach. Journal of Services Research, 14(2), 107-125.

Hair, J. F., Black, W. C., Babin, B. J., \& Anderson, R. E. (2019). Multivariate Data Analysis (8th ed.). Cengage.

Hayes, A. F., \& Coutts, J. J. (2020). Use omega rather than Cronbach's alpha for estimating reliability. But... . Communication Methods and Measures, 14(1), 1-24.

Huang, C., Wang, Y., Li, X., Ren, L., Zhao, J., Hu, Y., et al. (2020). Clinical features of patients infected with 2019 novel coronavirus in Wuhan, China. The Lancet, 395(10223), 497-506. 
Lin, C. Y. (2020). Social reaction toward the 2019 novel coronavirus (COVID-19). Social Health and Behavior, $3(1), 1-2$.

Mamun, M. A., \& Griffiths, M. D. (2020). First COVID-19 suicide case in Bangladesh due to fear of COVID-19 and xenophobia: possible suicide prevention strategies. Asian journal of psychiatry, 51, 102073.

Matthews, T., Danese, A., Caspi, A., Fisher, H. L., Goldman-Mellor, S., Kepa, A., \& Arseneault, L. (2019). Lonely young adults in modern Britain: findings from an epidemiological cohort study. Psychological Medicine, 49(2), 268-277.

Nasir, M., \& Adil, M. (2017). Service quality measurement in Indian hotels: factor structure and scale validation. Management Dynamics, 17(2), 11-24.

Nasir, M., \& Adil, M. (2020). Exploring the applicability of SERVPERF model in Indian two-wheeler industry: a CFA approach. International Journal of Productivity and Quality Management, 29(3), 329-354.

Noronha, P. (2020) "Indian economy to grow $9.5 \%$ in next fiscal year: fitch ratings", https://www.ndtv.com/ business/indian-economy-to-witnesfss-growth-of-9-5-in-next-fiscal-fitch-ratings-amid-covid19-coronavirus2244278

Pakpour, A. H., Griffiths, M. D., \& Lin, C. Y. (2020). Assessing psychological response to the COVID-19: the fear of COVID-19 scale and the COVID stress scales. International Journal of Mental Health and Addiction. https://doi.org/10.1007/s11469-020-00334-9.

Qiu, J., Shen, B., Zhao, M., Wang, Z., Xie, B., \& Xu, Y. (2020). A nationwide survey of psychological distress among Chinese people in the COVID-19 epidemic: implications and policy recommendations. General psychiatry, 33(2), e100213. https://doi.org/10.1136/gpsych-2020-100213.

Sadiq, M., \& Adil, M. (2021). The mediating role of customer satisfaction and its effect on service quality-customer loyalty link. International Journal of Productivity and Quality Management, 32(4), $520-535$.

Sadiq, M., Adil, M., \& Khan, M. N. (2019). Automated banks' service quality in developing economy: empirical evidences from India. International Journal of Services and Operations Management, 33(3), $331-350$.

Sadiq, M., Adil, M., \& Paul, J. (2021a). An innovation resistance theory perspective on purchase of eco-friendly cosmetics. Journal of Retailing and Consumer Services., 59, 102369.

Sadiq, M., Adil, M., \& Paul, J. (2021b). Does social influence turn pessimistic consumers green? Business Strategy and the Environment. https://doi.org/10.1002/bse.2780.

Sakib, N., Bhuiyan, A. I., Hossain, S., Al Mamun, F., Hosen, I., Abdullah, A. H., \& Sikder, M. T. (2020). Psychometric validation of the Bangla fear of COVID-19 scale: confirmatory factor analysis and Rasch analysis. International Journal of Mental Health and Addiction. https://doi.org/10.1007/s11469-020-00289$\mathrm{x}$.

Salhieh, L., Abu-Doleh, J., \& Hijazi, N. (2011). The assessment of e-banking readiness in Jordan. International Journal of Islamic and Middle Eastern Finance and Management, 4(4), 325-342.

Santini, Z. I., Jose, P. E., Cornwell, E. Y., Koyanagi, A., Nielsen, L., Hinrichsen, C., et al. (2020). Social disconnectedness, perceived isolation, and symptoms of depression and anxiety among older Americans (NSHAP): a longitudinal mediation analysis. The Lancet Public Health, 5(1), e62-e70.

Satici, B., Gocet-Tekin, E., Deniz, M. E., \& Satici, S. A. (2020). Adaptation of the fear of COVID-19 scale: Its association with psychological distress and life satisfaction in Turkey. International Journal of Mental Health and Addiction. https://doi.org/10.1007/s11469-020-00294-0.

Schimmenti, A., Billieux, J., \& Starcevic, V. (2020). The four horsemen of fear: an integrated model of understanding fear experiences during the COVID-19 pandemic. Clinical Neuropsychiatry, 17(2), 41-45.

Slavec, A., \& Drnovšek, M. (2012). A perspective on scale development in entrepreneurship research. Economic \& Business Review, 14(1), 39-62.

Soraci, P., Ferrari, A., Abbiati, F. A., Del Fante, E., De Pace, R., Urso, A., \& Griffiths, M. D. (2020). Validation and psychometric evaluation of the Italian version of the fear of COVID-19 scale. International Journal of Mental Health and Addiction. https://doi.org/10.1007/s11469-020-00277-1.

Taylor, S., Landry, C., Paluszek, M., Fergus, T. A., McKay, D., \& Asmundson, G. J. (2020). Development and initial validation of the COVID stress scales. Journal of Anxiety Disorders, 102232, 102232. https://doi.org/ 10.1016/j.janxdis.2020.102232.

Ullah, A., \& Adil, M. (2016). Service quality in supply chain: a case of Indian automotive industry. In In Innovative Solutions for Implementing Global Supply Chains in Emerging Markets (pp. 173-186). https:// doi.org/10.4018/978-1-4666-9795-9.ch012.

Wang, D., Hu, B., Hu, C., Zhu, F., Liu, X., Zhang, J., \& Zhao, Y. (2020). Clinical characteristics of 138 hospitalized patients with 2019 novel coronavirus-infected pneumonia in Wuhan, China. Jama, 323(11), 1061-1069.

Xiang, Y.-T. (2020). Timely mental health care for the 2019 novel coronavirus outbreak is urgently needed. Lancet Psychiatry, 7, 228-229. 
Zhang, J., Wu, W., Zhao, X., \& Zhang, W. (2020). Recommended psychological crisis intervention response to the 2019 novel coronavirus pneumonia outbreak in China: a model of West China hospital. Precision Clinical Medicine, 3(1), 3-8.

Zigmond, A. S., \& Snaith, R. P. (1983). The hospital anxiety and depression scale. Acta Psychiatrica Scandinavica, 67(6), 361-370.

Publisher's Note Springer Nature remains neutral with regard to jurisdictional claims in published maps and institutional affiliations.

\section{Affiliations}

\section{Mohd Nasir ${ }^{1} \cdot$ Mohd Adil $^{2} \cdot$ Mukesh Kumar $^{3}$}

Mohd Adil

profadilmohd@gmail.com

Mukesh Kumar

mukesh.kumariims@gmail.com

1 Faculty of Commerce, University of Allahabad, Allahabad, India

2 Department of Management Studies, NIT Hamirpur, Hamirpur, India

3 Faculty of Management Studies, Gopal Narayan Singh University, Sasaram, Jamuhar, India 